\title{
DE OUTRO MODO QUE SER: ALGUMAS OBSERVAÇÕES QUANTO À TRADUÇÃO PORTUGUESA DE AUTREMENT QU'ÊTRE OU AU-DELÀ DE L'ESSENCE
}

\author{
Otherwise than Being: some remarks about the portuguese translation of Autrement qu'être ou \\ au-delà de l'essence
}

Tiago dos Santos Rodrigues*

Resumo: O presente artigo apresenta o cotejo realizado entre a obra original do filósofo lituanofrancês Emmanuel Levinas, Autrement qu'être ou au-delà de l'essence, e sua versão em língua portuguesa, De outro modo que ser ou para lá da essência, primeira versão da obra no idioma de Camões. Esse texto apresenta as limitações da presente tradução, seja por trechos não traduzidos como de escolhas de tradução equivocadas. O texto original é sem dúvida deveras hermético, Levinas escreveu sua obra procurando uma linguagem própria, com uma linguagem que, na medida do possível, não estivesse contaminada pelo ser, pela ontologia. Para isso expressou-se do modo mais concreto possível sem que com isso sua expressão perde-se em rigor filosófico. A tradução, sem justificativa, desfez esse trabalho empreendido pelo autor que de modo algum é mero estilo literário, mas que constitui também o próprio conteúdo da obra.

Palavras-chave: Levinas, Tradução, Filosofia, Dizer.

\begin{abstract}
The article aims to present the collation accomplished between the original book from the Lithuanian-French philosopher Emmanuel Levinas (Autrement qu'être ou audelà de l'essence) and his translation into Portuguese (De outro modo que ser ou para lá da essência), which is the first translation into the Camoes idiom. The text shows some limitation of that translation such as no translated stretches and equivocated kinds of translation. The original text is undoubtedly hermetic. Levinas has written your book looking for an own language that as possible as could not be contaminated by the ontology. For that he has expressed himself in a concrete way without any kind of loss of philosophical accuracy. The translation unjustified has undone this Levinas work, which is not only a literary style but even book content.
\end{abstract}

Keywords: Levinas, Translation, Philosophy, Saying.

\footnotetext{
* Doutorando em Filosofia pela Pontifícia Universidade Católica do Rio Grande do Sul, bolsista CAPES. E-mail: tiagorodrigues1942@gmail.com
}

\begin{tabular}{|c|c|c|c|c|c|}
\hline intuitio & $\begin{array}{c}\text { ISSN } \\
1983-4012\end{array}$ & Porto Alegre & Vol.11 $-\mathrm{N}^{\mathrm{o} .1}$ & $\begin{array}{l}\text { Julho } \\
2018\end{array}$ & p.86-104 \\
\hline
\end{tabular}


Introdução

Toda tradução decorre de uma traição, assim como o Dizer é sempre traído no Dito. Há os que digam que a tradução mesma é coisa impossível ${ }^{1}$, mas ainda assim há de se conviver com o fato de que desde que um humano se encontrou com outro humano de língua distinta - e não suponho aqui a existência da escrita, mas tão só da fala -, os seres humanos traduzem, traduzem o dizer do outro ainda que o traindo - e, muitas vezes, que feliz traição! E talvez não estejamos equivocados em dizer que todo o nosso arcabouço cultural e técnico-científico é produto de traduções. Apesar do impossível, temos ido longe. Emmanuel Levinas experimentou a dificuldade que é aprender a língua do outro quando, saindo da sua Lituânia, se mudou para a França, e a dificuldade que constitui traduzir de uma língua que não é a sua para outra língua que também não é a materna ${ }^{2}$. O risco da traição é assumido porque é conversando que $a$ gente se entende, e é nesse sacrum commercium que a vida se vai produzindo e reproduzindo apesar dos pesares dos mal-entendidos dos quais a linguagem, se disse uma vez, é a fonte, contudo, todo o entendimento supõe, nesse sentido, o mal-entendido.

Este trabalho apresenta o cotejo realizado entre a versão portuguesa ${ }^{3}$ de Autrement qu'être ou audelà de l'essence, de Emmanuel Levinas, com a original francesa ${ }^{4}$, amparado também pela versão espanhola ${ }^{5}$. A versão portuguesa, infelizmente, se mostrou pródiga em deficiências. De mais grave: há no mínimo nove passagens injustificadamente omitidas e um parágrafo com sentido adulterado. Principalmente a partir da página 108 inicia-se uma série de trechos excluídos ${ }^{6}$. Como se trata de um número elevado de ocorrências e bem localizadas no corpo do texto, cremos que não pode ter sido mero azar no trabalho. A versão portuguesa se mostrou também infeliz ao traspor muitos termos. Levinas utiliza várias palavras da linguagem ordinária, ou como chama François-David Sebbah: imagens terrificantes ${ }^{7}$. A tradução resolveu cambiá-los para termos mais científicos, mais ao gosto do paladar acadêmico ${ }^{8}$. Isso não só retirou a expressividade própria do filósofo como também fez com que o texto perdesse o toque de concretude ética a que ele se propõe para fugir da linguagem ontológica. Outra opção de tradução que

1 Cf. ECO, U. Decir casi lo mismo. Trad: Helena Lozano Meireles. Barcelona: Debolsillo, 2009. p. 24.

2 É de Levinas a primeira tradução do original alemão para o francês das Meditações Cartesianas de Edmund Husserl. Essa tradução, feita em conjunto com Gabrielle Peiffer, revista por Alexandre Koyré, e publicada em 1931, não deixa de possuir deficiências terminológicas e infidelidades ao texto original. C.f. ALVES, Pedro M. S. "Apresentação da tradução portuguesa". In. HUSSERL, E. Meditações cartesianas e Conferências de Paris. Trad: Pedro M. S. Alves. - 1. ed. - Rio de janeiro: Forense, 2013. p. IX-XII.

${ }^{3}$ LEVINAS. E. De outro modo que ser ou para lá da essência. Trad. José Luis Pérez, Lavínia Leal Pereira. Lisboa: Centro de Filosofia da Universidade de Lisboa, 2011.

${ }^{4}$ LEVINAS. E. Autrement qu'être ou au-delà de l'essence. Martinus Nijhoff, 1978.

${ }^{5}$ LEVINAS. E. De otro modo que ser ou más allá de la esencia. Trad. Antonio Pintor Ramos. Salamanca: Edicones Sigueme, 2003.

6 Esta série inicia-se a partir do ponto 29 deste artigo; na tradução, se estende até a página 165.

7 Cf. SEBBAH, F. Levinas. Trad: Guilherme João de Freitas Teixeira. São Paulo: Estação Liberdade, 2009. p. 27.

8 Essas trocas de termos, fazemos notar nos seguintes pontos deste trabalho: 8, 17, 20, 21, 22, 23.

\begin{tabular}{|c|c|l|l|l|l|}
\hline intuitio & $\begin{array}{c}\text { ISSN } \\
1983-4012\end{array}$ & Porto Alegre & Vol.11- $\mathrm{N}^{\circ} .1$ & $\begin{array}{l}\text { Julho } \\
2018\end{array}$ & p.86-104 \\
\hline
\end{tabular}


De Outro Modo Que Ser: algumas observações quanto à tradução portuguesa de

Autrement qu'être ou au-delà de l'essence consideramos infeliz foi a implosão do termo assigner $^{9}$ que recorrentemente aparece no texto por meio de cinco outros termos próximos a ele - tal procedimento fez com que o conceito perdesse em força pela dificuldade que pode daí decorrer aos desavisados em associar tantos termos diferentes a uma mesma noção. A tradução poderia recorrer a vários recursos quanto a isso: notas, parênteses ou colchetes para justificar as suas opções ou, ao menos, dar a conhecer o termo original ali presente, mas não o faz. O texto segue corrido com escassas notas do tradutor (N.T.), três somente. Claro que a quantidade de notas do tradutor numa obra traduzida não traduzem o rigor ou a qualidade da mesma, é questão sempre relativa, no entanto, visto que a introdução da edição portuguesa nada fala da tradução propriamente dita, mas somente do desenvolvimento da obra, e visto que não há um glossário dos termos cambiados, a tradução ficou devendo uma maior criticidade. Pode ser que algumas traduções prefiram não exagerar em notas, parênteses ou colchetes para que a leitura do texto seja mais fluída e menos truncada, contudo é de se questionar o que vale uma leitura mais fluída, porém, menos compreensiva do texto original ${ }^{10}$. As dificuldades de uma leitura truncada pela presença de notas e similares podem muito bem ser menosprezadas na medida em que colaboram numa melhor compreensão do texto - que é o que realmente interessa. Além do mais, o texto levinasiano é deveras hermético, não encontramos simplesmente um texto em língua francesa, mas também em língua levinasiana. Muitos esclarecimentos deveriam ter sido prestados ao leitor em relação às escolhas da tradução. E ainda que a versão espanhola muitas vezes pareça ser mais simples, direta e por isso, de certa forma, mais fiel ao texto original, existem trechos em que no mínimo alguém também dormiu no ponto. Por exemplo, no texto original encontramos: "Jouissance de la jouissance avant toute réflexion, mais sans se tourner dans la jouissance vers la jouissance comme la vision se tourne vers le "vu""11. Mas na espanhola encontramos isto: "Gozo del Gozar anterior a toda reflexión, pero retorno en el gozar hacia el gozo, como la visión se vuelve hacia el "visto""12. O que é dito aqui é exatamente o contrário do que é dito no original, omitindo-se a distinção que há entre o modo da fruição e entre o modo da visão. Há outros trechos em que também não entramos de acordo com as escolhas realizadas pela versão espanhola, preferindo a portuguesa, e trechos que foram efetivamente traduzidos de forma equivocada, sem contar um e outro trecho que também não foram traduzidos. Entretanto, da versão espanhola não podemos fazer maior juízo porque não foi lida integralmente, só foi consultada quando se achava necessário e nessas consultas perceberam-se as tais

\footnotetext{
9 Ver neste trabalho o ponto 1.

10 "Es decir, que cuando compro la traducción de una obra estranjera, ya sea ua novela o un tratado de sociología (y sabendo desde luego que en el primer caso me arriesgo más que en el segundo), espero que la traducción pueda decirme lo mejor posible lo que estaba escrito en el original". ECO, U. Decir casi lo mismo. Trad: Helena Lozano Meireles. Barcelona: Debolsillo, 2009. p. 29.

${ }^{11}$ LEVINAS. E. Autrement qu'être ou au-delà de l'essence. Martinus Nijhoff, 1978. p. 118.

12 LEVINAS. E. De otro modo que ser ou más allá de la esencia. Trad. Antonio Pintor Ramos. Salamanca: Edicones Sigueme, 2003. p. 132.
}

\begin{tabular}{|c|c|c|c|c|c|}
\hline intuitio & $\begin{array}{c}\text { ISSN } \\
1983-4012\end{array}$ & Porto Alegre & Vol.11 - No.1 & $\begin{array}{l}\text { Julho } \\
2018\end{array}$ & p.86-104 \\
\hline
\end{tabular}


De Outro Modo Que Ser: algumas observações quanto à tradução portuguesa de

Autrement qu'être ou au-delà de l'essence deficiências ${ }^{13}$. Muitos dos pontos levantados não se referem propriamente a erros de tradução, mas também em sugestões de tradução ou em esclarecimentos que se julgou serem importantes ${ }^{14}$. A exposição da análise feita foi organizada da seguinte forma:

a) Cada ponto se refere a somente um trecho da obra.

b) A sequência dos pontos não está organizada segundo temas (trechos não traduzidos, palavras mal-empregadas e etc.), mas segue a numeração das páginas da versão portuguesa.

c) O número da página referido no início de cada ponto é referente ao número da página da tradução portuguesa; as citações em francês e espanhol estão devidamente notadas no rodapé da página com o número das páginas onde os trechos se encontram nessas edições.

d) Os pontos precedidos por asterisco $\left(^{*}\right)$ são os que se consideram serem erros de tradução, isto é, palavra ou expressão mal-empregada ou ausência de trecho.

\section{Pontos Destacados}

1. O termo assigner é traduzido por convocação/convocar/convocado, intimação/intimar/intimado, imputação/imputar/imputado, designação/designar/designado, incumbência/incumbir/incumbido.

2. O termo trace é traduzido por rasto - com exceção de uma única ocorrência; na página 176 está escrito: "Traço fugitivo que se apaga e reaparece [...]"15. A francesa diz: "Trace fuyante s'effaçant et réapparaissant [...]"16.

3. O termo concerner, embora tenha correlativo no português (concernir), foi traduzido por dizer respeito ou diz respeito. Isso não significa que toda a vez que dizer respeito aparecer no texto seja o verbo concerner que ali esteja. A edição francesa diz: "Le psychisme de l'intentionnalité, par-delà la corrélation du Dit et du Dire, tient à la signifiance du Dire et de l'incarnation"17; a portuguesa traduz: "O psiquismo da intencionalidade, para lá da correlação do Dito e do Dizer, diz respeito à significância do Dizer e da encarnação" ${ }^{18}$.

${ }^{13}$ Por conta disso aconselhamos que aos que forem ler a obra na edição de língua espanhola, possam, na medida do possível, estarem também amparados pela versão original.

${ }^{14}$ Como, por exemplo, os pontos 2, 3, 4, 7, 9, 11 e 60.

${ }^{15}$ LEVINAS. E. De outro modo que ser ou para lá da essência. Trad. José Luis Pérez, Lavínia Leal Pereira. Lisboa: Centro de Filosofia da Universidade de Lisboa, 2011. p. 176.

${ }^{16}$ LEVINAS. E. Autrement qu'être ou au-delà de l'essence. Martinus Nijhoff, 1978., p. 252.

${ }^{17}$ LEVINAS. E. Autrement qu'être ou au-delà de l'essence. Martinus Nijhoff, 1978. p. 112.

${ }^{18}$ LEVINAS. E. De outro modo que ser ou para lá da essência. Trad. José Luis Pérez, Lavínia Leal Pereira. Lisboa: Centro de Filosofia da Universidade de Lisboa, 2011. p. 88.

\begin{tabular}{|c|c|l|l|l|l|}
\hline intuitio & $\begin{array}{c}\text { ISSN } \\
1983-4012\end{array}$ & Porto Alegre & Vol.11- $\mathrm{N}^{\circ} .1$ & $\begin{array}{l}\text { Julho } \\
2018\end{array}$ & p.86-104 \\
\hline
\end{tabular}


De Outro Modo Que Ser: algumas observações quanto à tradução portuguesa de

Autrement qu'être ou au-delà de l'essence

4. $\mathrm{O}$ termo espèce é recorrentemente traduzido por forma. A edição francesa diz, por exemplo: "Sous les espèces de la responsabilité"19; a portuguesa traduz na página 88: "Sob as formas da responsabilidade" 20 . Isso também não significa que toda a vez que o termo forma aparecer no texto seja o termo espèce que ali se encontre. A edição francesa diz, por exemplo: "Le psychisme ou l'animation c'est la façon dont une telle différence entre l'un et l'autre [...]"21; a portuguesa traduz na página 89: "O psiquismo ou a animação é a forma pela qual uma tal diferença entre o um e o outro [...]”.

5. * Na página 33 está escrito: “[...] mas em razão da sua incomensurabilidade como presente" 22 . A francesa diz: "[...] mais en raison de son incommensurabilité avec le présent". Cremos que houve ao menos um erro na digitação, pois haveria de se deixar "com o presente".

6. Na página 48 está escrito: "Se não escutamos a interpelação [...]"23. O original diz: "Si on est sourd à la demande [...]"24. A espanhola: "Si se es sordo a la peticion [...]"25. A espanhola traduz melhor não somente a letra como também a intenção, de que esse não escutar carrega também alguma responsabilidade e não é mero azar desculpável.

7. Na página 66 a frase destacada, "todas as profundezas da terra são abaladas pela injustiça" ${ }^{26}$ é referência não literal ao Salmo 11 - a edição francesa também não traz a referência.

8. Na página 68 está escrito: "Dizer é aproximar-se do próximo, 'dar-lhe significação”, e: "Significação dada ao outro, anteriormente a toda a objectivação"27. O original diz: "Dire, c'est approcher le prochain, lui "bailler signifiance"”28, e: "Signifiance baillée à l'autre, antérieurement à toute objectivation". A espanhola traduz por "[...] acreditarle significación", e, "significación concedida"29. Bailler é bocejar. Dizer é bocejar significação. Cremos que assim é que deve ser traduzida e lida essa passagem. Recordamos aqui que o Aleph, aquela primeira letra do alfabeto hebraico, aquele primeiro mandamento do judaísmo, não é propriamente pronunciado, dado em sentido positivo, ele é como mesmo

${ }^{19}$ LEVINAS. E. Autrement qu'être ou au-delà de l'essence. Martinus Nijhoff, 1978. p. 11.

${ }^{20}$ LEVINAS. E. De outro modo que ser ou para lá da essência. Trad. José Luis Pérez, Lavínia Leal Pereira. Lisboa: Centro de Filosofia da Universidade de Lisboa, 2011. p. 88.

${ }^{21}$ LEVINAS. E. Autrement qu'être ou au-delà de l'essence. Martinus Nijhoff, 1978. p. 114.

${ }^{22}$ LEVINAS. E. De outro modo que ser ou para lá da essência. Trad. José Luis Pérez, Lavínia Leal Pereira. Lisboa: Centro de Filosofia da Universidade de Lisboa, 2011. p.33.

${ }^{23}$ LEVINAS. E. De outro modo que ser ou para lá da essência. Trad. José Luis Pérez, Lavínia Leal Pereira. Lisboa: Centro de Filosofia da Universidade de Lisboa, 2011. p. 48.

${ }^{24}$ LEVINAS. E. Autrement qu'être ou au-delà de l'essence. Martinus Nijhoff, 1978. p. 48.

${ }^{25}$ LEVINAS. E. De otro modo que ser ou más allá de la esencia. Trad. Antonio Pintor Ramos. Salamanca: Edicones Sigueme, 2003. p. 73.

${ }^{26}$ LEVINAS. E. De outro modo que ser ou para lá da essência. Trad. José Luis Pérez, Lavínia Leal Pereira. Lisboa: Centro de Filosofia da Universidade de Lisboa, 2011. p. 66.

${ }^{27}$ LEVINAS. E. De outro modo que ser ou para lá da essência. Trad. José Luis Pérez, Lavínia Leal Pereira. Lisboa: Centro de Filosofia da Universidade de Lisboa, 2011. p. 68.

${ }^{28}$ LEVINAS. E. Autrement qu'être ou au-delà de l'essence. Martinus Nijhoff, 1978., p. 81.

${ }^{29}$ LEVINAS. E. De otro modo que ser ou más allá de la esencia. Trad. Antonio Pintor Ramos. Salamanca: Edicones Sigueme, 2003. p. 100.

\begin{tabular}{|c|c|c|c|c|c|}
\hline intuitio & $\begin{array}{c}\text { ISSN } \\
1983-4012\end{array}$ & Porto Alegre & Vol.11- $\mathrm{N}^{\mathrm{o}} .1$ & $\begin{array}{l}\text { Julho } \\
2018\end{array}$ & p.86-104 \\
\hline
\end{tabular}


De Outro Modo Que Ser: algumas observações quanto à tradução portuguesa de

Autrement qu'être ou au-delà de l'essence que soprado, o que validaria esse bocejo do Dizer na proximidade. Essa opção de tradução reaparecerá na página 97.

9. Na página 69 está escrito: “O sujeito do Dizer não dá sinal, ele faz-se signo, afasta-se em fidelidade"30. O original diz: "Le sujet du Dire ne donne pas signe, il se fait signe, $s$ 'en va en allégeance"31. A espanhola diz: "[...] se convierte em vasallaje" ${ }^{32}$. A expressão é de difícil tradução. Ambas as traduções, portuguesa e espanhola, são válidas, pois trazem a ideia expressa de estar em condição de subordinação. Mas talvez uma versão mais feliz para o português seria justamente uma mescla das opções apresentadas: se converte em fidelidade.

10. * Na página 70, a nota de número 35 tem um erro crasso na construção das frases (algumas trocas desnecessárias e duplicações) que, felizmente, não chegam a comprometer a compreensão do texto nem fazem soar qualquer contradição no pensamento desenvolvido ${ }^{33}$. Começa a partir da frase: "A proximidade vai de alma em alma [...]"34 e segue nas cinco próximas linhas. Não reproduzimos aqui porque seria muito extenso e julgamos ser desnecessário, uma simples olhada nas duas versões já faz perceber.

11. Na página 71, está escrito: “[...] não cessa de morrer, dura no seu instante, faz-se velho"35. O original diz: "[...] ne cesse de mourir, dure dans son instant, blanchit sous le harnais"36. A espanhola diz: “[...] resplandece bajo los arrestos" ${ }^{37}$. Blanchit sous le harnais é uma expressão idiomática que se diz de quem tem larga experiência em fazer algo. Assim se justifica a tradução portuguesa.

12. Na página 73 está escrito: “A identidade do mesmo no 'eu' advém a partir de fora, sem que ele queira [...]"38. O original diz: "L'identité du même dans le 'je' lui vient malgré soi du dehors, comme une élection [...]"39. A espanhola conserva como "a su pesar"40. Malgré soi é reinterpretado sem necessidade e impropriamente. Isso porque é dito dois parágrafos antes (e a versão portuguesa reproduz

${ }^{30}$ LEVINAS. E. De outro modo que ser ou para lá da essência. Trad. José Luis Pérez, Lavínia Leal Pereira. Lisboa: Centro de Filosofia da Universidade de Lisboa, 2011. p. 69.

${ }^{31}$ LEVINAS. E. Autrement qu'être ou au-delà de l'essence. Martinus Nijhoff, 1978. p. 83.

${ }^{32}$ LEVINAS. E. De otro modo que ser ou más allá de la esencia. Trad. Antonio Pintor Ramos. Salamanca: Edicones Sigueme, 2003. p. 102.

${ }^{33}$ No original: LEVINAS. E. Autrement qu'être ou au-delà de l'essence. Martinus Nijhoff, 1978. p. 84, nota 1.

${ }^{34}$ LEVINAS. E. De outro modo que ser ou para lá da essência. Trad. José Luis Pérez, Lavínia Leal Pereira. Lisboa: Centro de Filosofia da Universidade de Lisboa, 2011. p. 70.

${ }^{35}$ LEVINAS. E. De outro modo que ser ou para lá da essência. Trad. José Luis Pérez, Lavínia Leal Pereira. Lisboa: Centro de Filosofia da Universidade de Lisboa, 2011. p 71.

${ }^{36}$ LEVINAS. E. Autrement qu'être ou au-delà de l'essence. Martinus Nijhoff, 1978. p. 86.

${ }^{37}$ LEVINAS. E. De otro modo que ser ou más allá de la esencia. Trad. Antonio Pintor Ramos. Salamanca: Edicones Sigueme, 2003. p. 104.

${ }^{38}$ LEVINAS. E. De outro modo que ser ou para lá da essência. Trad. José Luis Pérez, Lavínia Leal Pereira. Lisboa: Centro de Filosofia da Universidade de Lisboa, 2011. p. 73.

${ }^{39}$ LEVINAS. E. Autrement qu'être ou au-delà de l'essence. Martinus Nijhoff, 1978. p. 88.

${ }^{40}$ LEVINAS. E. De otro modo que ser ou más allá de la esencia. Trad. Antonio Pintor Ramos. Salamanca: Edicones Sigueme, 2003. p. 106.

\begin{tabular}{|c|c|l|l|l|l|}
\hline intuitio & $\begin{array}{c}\text { ISSN } \\
1983-4012\end{array}$ & Porto Alegre & Vol.11- $\mathrm{N}^{\circ} .1$ & $\begin{array}{l}\text { Julho } \\
2018\end{array}$ & p.86-104 \\
\hline
\end{tabular}


De Outro Modo Que Ser: algumas observações quanto à tradução portuguesa de

Autrement qu'être ou au-delà de l'essence literalmente) o seguinte trecho: "Le malgré ne s'oppose pas ici au gré, à une volonté" 41 . Isto é, não se pode falar de um "sem que ele queira" porque não se trata de querer ou não querer, o apesar de si (malgré soi) é anterior ao querer, pois este supõe uma vontade estabelecida, e, portanto, uma liberdade atuante - o que não é o caso. Malgré ainda aparecerá sem ser traduzido por apesar de (quando pensamos que deveria) na página 78 (está traduzido por "pese embora").

13. Na página 73 está escrito: “[...] numa obediência sem deserção onde a revolta se prepara" ${ }^{42}$. O original diz: "[...] dans une obéissance sans désertion où la révolte mijote" ${ }^{43}$. A espanhola traduz por: "[...] la rebelión va cociendo a fuego lento" 4 . De fato, mijoter é cozinhar em fogo brando. Quem sabe o melhor aqui fosse reproduzir ou dar em nota o sentido da expressão (cozinhar em fogo brando).

14. Na página 75 está escrito: "um crescimento da dívida num sujeito que não se recupera, que "não ganha para as despesas" 45 . O original diz: "un accroissement de dette dans un sujet qui ne se ressaisit pas, qui "ne joint pas les deux bouts"46. A espanhola traduz por: "que no une los dos extremos"47. A portuguesa aqui foi mais feliz, ne joint pas les deux bouts se diz quando não se tem dinheiro até o fim do mês.

15. * Na página 79 está escrito: “[...] numa responsabilidade irrecusável, eu me ponho como deposto da minha soberania" ${ }^{48}$. O original diz: “[...] dans une responsabilité irrécusable, je me pose déposé de ma souveraineté" ${ }^{49}$. A espanhola é literal ${ }^{50}$. Não pensamos haver necessidade alguma de introduzir esse como. E, na nossa leitura, pensamos ser ele indesejado ali, pois traz uma ambiguidade, afinal, não é que o sujeito esteja de um modo análogo a uma deposição de soberania, a um como se fosse isso. O sujeito, isso sim, se encontra realmente nessa situação, ele está, de fato, e eticamente, deposto dela. A anterioridade de outrem não é uma metáfora.

${ }^{41}$ LEVINAS. E. Autrement qu'être ou au-delà de l'essence. Martinus Nijhoff, 1978. p. 86.

${ }^{42}$ LEVINAS. E. De outro modo que ser ou para lá da essência. Trad. José Luis Pérez, Lavínia Leal Pereira. Lisboa: Centro de Filosofia da Universidade de Lisboa, 2011. p. 73.

${ }^{43}$ LEVINAS. E. Autrement qu'être ou au-delà de l'essence. Martinus Nijhoff, 1978. p. 88.

${ }^{44}$ LEVINAS. E. De otro modo que ser ou más allá de la esencia. Trad. Antonio Pintor Ramos. Salamanca: Edicones Sigueme, 2003. p. 106.

${ }^{45}$ LEVINAS. E. De outro modo que ser ou para lá da essência. Trad. José Luis Pérez, Lavínia Leal Pereira. Lisboa: Centro de Filosofia da Universidade de Lisboa, 2011. p. 75.

${ }^{46}$ LEVINAS. E. Autrement qu'être ou au-delà de l'essence. Martinus Nijhoff, 1978. p. 93.

${ }^{47}$ LEVINAS. E. De otro modo que ser ou más allá de la esencia. Trad. Antonio Pintor Ramos. Salamanca: Edicones Sigueme, 2003. p. 110.

${ }^{48}$ LEVINAS. E. De outro modo que ser ou para lá da essência. Trad. José Luis Pérez, Lavínia Leal Pereira. Lisboa: Centro de Filosofia da Universidade de Lisboa, 2011. p. 79.

${ }^{49}$ LEVINAS. E. Autrement qu'être ou au-delà de l'essence. Martinus Nijhoff, 1978. p. 99.

${ }^{50}$ LEVINAS. E. De otro modo que ser ou más allá de la esencia. Trad. Antonio Pintor Ramos. Salamanca: Edicones Sigueme, 2003. p. 115.

\begin{tabular}{|c|c|l|l|l|l|}
\hline intuitio & $\begin{array}{c}\text { ISSN } \\
1983-4012\end{array}$ & Porto Alegre & Vol.11- $\mathrm{N}^{\circ} .1$ & $\begin{array}{l}\text { Julho } \\
2018\end{array}$ & p.86-104 \\
\hline
\end{tabular}


De Outro Modo Que Ser: algumas observações quanto à tradução portuguesa de

Autrement qu'être ou au-delà de l'essence

16. * Na página 82 está escrito: “[...] coisa que é reconhecida, desde há muito, sob o título de espontaneidade do entendimento" 51 . O original diz: “[...] ce que l'on reconnaît depuis longtemps en philosophie sous le titre de spontanéité de l'entendement"52. A versão portuguesa simplesmente extirpou filosofia da frase.

17. Na página 84 está escrito: “[...] a inversão do outro que inspira o mesmo - dor, extravasamento do sentido pelo sem sentido, [...]"53. O original diz: “[...] le renversement de l'autre inspirant la même douleur, débordement du sens par le non-sens [...]"54. A espanhola traduz por: "desbordamiento" $"$. Ainda que o sentido de extravasamento seja próximo ao de débordement, cremos que se poderia ter optado pelo termo correlativo em português: transbordamento.

18. * Na página 84 está escrito: "O presente da manifestação - origem do próprio facto da origem - é origem $d a$ filosofia" ${ }^{56}$. O original diz: "Le présent de la manifestation origine du fait même de l'origine est origine pour la philosophie"57. A espanhola traduz por: "para la"58. A versão portuguesa dá a entender que Levinas esteja fazendo uma afirmação ratificadora, quando, na verdade, ele a põe em questão; a filosofia tem para si como origem tal coisa, haverá de se mostrar que é, ou ao menos pode ser, outra coisa.

19. * Na página 86 está escrito: “Que a essência do ser torne possível, através desta essência mesma, a verdade, e eis que o sujeito - seja qual for o nome que lhe atribuamos - é inseparável do aparecer da intencionalidade"59. O original diz: "Que 1'essence de l'être rende possible, de par cette essence même la vérité, et voilà que le sujet quel que soit le nom qu'on lui donne est inséparable du savoir de l'apparoir de l'intentionnalité" ${ }^{60}$. A versão portuguesa extirpou o du savoir. A espanhola manteve por: "del saber" 61 . Pensamos que deveria se manter, pois entre o saber do aparecer da intencionalidade e o simples aparecer da intencionalidade, não há pouca diferença.

${ }^{51}$ LEVINAS. E. De outro modo que ser ou para lá da essência. Trad. José Luis Pérez, Lavínia Leal Pereira. Lisboa: Centro de Filosofia da Universidade de Lisboa, 2011. p. 82.

52 LEVINAS. E. Autrement qu'être ou au-delà de l'essence. Martinus Nijhoff, 1978. p. 102.

${ }^{53}$ LEVINAS. E. De outro modo que ser ou para lá da essência. Trad. José Luis Pérez, Lavínia Leal Pereira. Lisboa: Centro de Filosofia da Universidade de Lisboa, 2011. p. 84.

${ }^{54}$ LEVINAS. E. Autrement qu'être ou au-delà de l'essence. Martinus Nijhoff, 1978. p. 105.

${ }^{55}$ LEVINAS. E. De otro modo que ser ou más allá de la esencia. Trad. Antonio Pintor Ramos. Salamanca: Edicones Sigueme, 2003. p. 121.

${ }^{56}$ LEVINAS. E. De outro modo que ser ou para lá da essência. Trad. José Luis Pérez, Lavínia Leal Pereira. Lisboa: Centro de Filosofia da Universidade de Lisboa, 2011. p. 84.

${ }^{57}$ LEVINAS. E. Autrement qu'être ou au-delà de l'essence. Martinus Nijhoff, 1978. p. 105.

${ }^{58}$ LEVINAS. E. De otro modo que ser ou más allá de la esencia. Trad. Antonio Pintor Ramos. Salamanca: Edicones Sigueme, 2003. p. 121.

${ }^{59}$ LEVINAS. E. De outro modo que ser ou para lá da essência. Trad. José Luis Pérez, Lavínia Leal Pereira. Lisboa: Centro de Filosofia da Universidade de Lisboa, 2011. p. 86.

${ }^{60}$ LEVINAS. E. Autrement qu'être ou au-delà de l'essence. Martinus Nijhoff, 1978. p. 108.

${ }^{61}$ LEVINAS. E. De otro modo que ser ou más allá de la esencia. Trad. Antonio Pintor Ramos. Salamanca: Edicones Sigueme, 2003. p. 123.

\begin{tabular}{|c|c|c|c|c|c|}
\hline intuitio & $\begin{array}{c}\text { ISSN } \\
1983-4012\end{array}$ & Porto Alegre & Vol.11- $\mathrm{N}^{\mathrm{o}} .1$ & $\begin{array}{l}\text { Julho } \\
2018\end{array}$ & p.86-104 \\
\hline
\end{tabular}


De Outro Modo Que Ser: algumas observações quanto à tradução portuguesa de

Autrement qu'être ou au-delà de l'essence

20. Na página 89 está escrito: “[...] o que equivale a toda a gravidade de um corpo animado, ou seja, oferecido a outrem, exprimindo-se ou expandindo-se!"62. O original diz: "[...] ce qui équivaut à toute la gravité d'un corps animé, c'est-à-dire offert à autrui, s'exprimant ou s'épanchant!"63. A espanhola traduz por: "derramarse" ${ }^{64}$. A espanhola foi mais fiel, mas é importante comentar que o derramar-se do s'épanchant é o derramar-se de um amigo ao outro, quando se vai, por exemplo, confidenciar coisas ao outro, é propriamente uma oferta que se faz de si - como se refere na mesma frase.

21. Na página 91 está escrito: "Dissipação nunca suficientemente dissipada" ${ }^{65}$. O original diz: "Engloutissement jamais assez engloutissant, [...]"66. A espanhola diz: "Engullimiento nunca suficientemente engullente, $[\ldots]^{\prime 67}$. Novamente cremos que deveria se manter a originalidade da versão francesa e ter-se optado por algo como engolimentolengolível.

22. * Na página 92 está escrito: “A significação - o um-para-o-outro - não tem sentido senão entre seres de carne e osso". O original diz: "La signification l'un-pour-l'autre n'a de sens qu'entre êtres de chair et de sang" ${ }^{\prime 68}$. Sang é sangue, a tradução portuguesa opta por cambiar sang por osso em todas as ocorrências da expressão chair et de sang, isso ocorre também nas páginas 95, 96, 97 e 157. Carne e osso talvez seja uma expressão mais recorrente em português para se referir que alguém seja real e esteja vivo. Porém, cremos que deveria ter se mantido a expressão original tal e qual porque o sangue na tradição semita é o portador da vida. O interdito ao assassinato do outro é a proibição de "derramar sangue". Carne e osso perde essa significância assim como a referência à tradição semita que é explícita.

23. Na página 92 está escrito: “[...] à vida onde a significação - o para-o-outro - se absorve, à vida que vive ou que frui a vida"69. O original diz: “[...] à la vie où la signification le pour-l'autre s'engloutit, à la vie vivant ou jouissant de vie"70. A espanhola traduz por: "se engulle" ${ }^{\text {"71 }}$. De novo, cremos que deveria se manter o original e se optar por se engole.

${ }^{62}$ LEVINAS. E. De outro modo que ser ou para lá da essência. Trad. José Luis Pérez, Lavínia Leal Pereira. Lisboa: Centro de Filosofia da Universidade de Lisboa, 2011. p. 89.

${ }^{63}$ LEVINAS. E. Autrement qu'être ou au-delà de l'essence. Martinus Nijhoff, 1978. p. 114.

${ }^{64}$ LEVINAS. E. De otro modo que ser ou más allá de la esencia. Trad. Antonio Pintor Ramos. Salamanca: Edicones Sigueme, 2003. p. 128.

${ }^{65}$ LEVINAS. E. De outro modo que ser ou para lá da essência. Trad. José Luis Pérez, Lavínia Leal Pereira. Lisboa: Centro de Filosofia da Universidade de Lisboa, 2011. p. 91.

${ }^{66}$ LEVINAS. E. Autrement qu'être ou au-delà de l'essence. Martinus Nijhoff, 1978. p. 117.

${ }^{67}$ LEVINAS. E. De otro modo que ser ou más allá de la esencia. Trad. Antonio Pintor Ramos. Salamanca: Edicones Sigueme, 2003. p. 131.

${ }^{68}$ LEVINAS. E. Autrement qu'être ou au-delà de l'essence. Martinus Nijhoff, 1978. p. 119.

${ }^{69}$ LEVINAS. E. De outro modo que ser ou para lá da essência. Trad. José Luis Pérez, Lavínia Leal Pereira. Lisboa: Centro de Filosofia da Universidade de Lisboa, 2011. p. 92.

${ }^{70}$ LEVINAS. E. Autrement qu'être ou au-delà de l'essence. Martinus Nijhoff, 1978. p. 119.

${ }^{71}$ LEVINAS. E. De otro modo que ser ou más allá de la esencia. Trad. Antonio Pintor Ramos. Salamanca: Edicones Sigueme, 2003. p. 132.

\begin{tabular}{|c|c|c|c|c|c|}
\hline intuitio & $\begin{array}{c}\text { ISSN } \\
1983-4012\end{array}$ & Porto Alegre & Vol.11- $\mathrm{N}^{\mathrm{o}} .1$ & $\begin{array}{l}\text { Julho } \\
2018\end{array}$ & p.86-104 \\
\hline
\end{tabular}


De Outro Modo Que Ser: algumas observações quanto à tradução portuguesa de

Autrement qu'être ou au-delà de l'essence

24. Na página 95 está escrito: “[...] intriga onde estou atado aos outros antes de estar ligado ao meu corpo"72. O original diz: "[...] intrigue où je suis noué aux autres avant d'être noué à mon corps"73. Pensamos que deveria se manter o termo original e optado por atado como na primeira ocorrência.

25. Na página 95 está escrito: "Mas o Dizer estendido sobre o Dito [...]"74. O original diz: "Mais le Dire tendu vers le Dit [...]"75. A espanhola traduz por: "hasta"76. Vers tem conotação de direção e não de sobreposição, nesse sentido pensamos que a escolha da versão espanhola é melhor, e para o português seria melhor algo como "até o...".

26. * Na página 104 está escrito: “[...] o próximo, o primeiro que aparece [...]"”77. O original diz: "[...] le prochain, premier venu [...]" ${ }^{\prime 78}$. A espanhola traduz por: primer venido ${ }^{79}$. A espanhola está correta, o próximo é aquele que vem, mas não aparece. Isso mesmo é dito logo em seguida no mesmo parágrafo: "[...] le prochain me concerne par sa singularité exclusive sans apparaître [...]"80. Premier venu é erroneamente traduzido novamente como primeiro que aparece no início do parágrafo que segue.

27. Na página 106 está escrito: "Recuperar-se para um presente de acolhimento é já ganhar distância e falhar o próximo" 81 . O original diz: "Se ressaisir pour un présent d'accueil c'est déjà prendre distance et manquer le prochain" $"$. A espanhola traduz por: "esquivar" ${ }^{\text {" }}$. Manquer aqui possui o sentido de perder, se perde o próximo pela distância tomada.

28. Na página 106 está escrito: “[...] num passado mais profundo que tudo aquilo que eu sou, que estou em posição de reunir pela memória [...]”"84. O original diz: “[...] dans un passé plus profond que tout ce que je suis à même de rassembler par la mémoire [...]"85. A espanhola traduz por "yo soy capaz"\$6.

${ }^{72}$ LEVINAS. E. De outro modo que ser ou para lá da essência. Trad. José Luis Pérez, Lavínia Leal Pereira. Lisboa: Centro de Filosofia da Universidade de Lisboa, 2011. p. 95.

${ }^{73}$ LEVINAS. E. Autrement qu'être ou au-delà de l'essence. Martinus Nijhoff, 1978. p. 123.

${ }^{74}$ LEVINAS. E. De outro modo que ser ou para lá da essência. Trad. José Luis Pérez, Lavínia Leal Pereira. Lisboa: Centro de Filosofia da Universidade de Lisboa, 2011. p. 95.

${ }^{75}$ LEVINAS. E. Autrement qu'être ou au-delà de l'essence. Martinus Nijhoff, 1978. p. 124.

${ }^{76}$ LEVINAS. E. De otro modo que ser ou más allá de la esencia. Trad. Antonio Pintor Ramos. Salamanca: Edicones Sigueme, 2003. p. 136.

${ }^{77}$ LEVINAS. E. De outro modo que ser ou para lá da essência. Trad. José Luis Pérez, Lavínia Leal Pereira. Lisboa: Centro de Filosofia da Universidade de Lisboa, 2011. p. 104.

${ }^{78}$ LEVINAS. E. Autrement qu'être ou au-delà de l'essence. Martinus Nijhoff, 1978. p. 137.

${ }^{79}$ LEVINAS. E. De otro modo que ser ou más allá de la esencia. Trad. Antonio Pintor Ramos. Salamanca: Edicones Sigueme, 2003. p. 147.

${ }^{80}$ LEVINAS. E. Autrement qu'être ou au-delà de l'essence. Martinus Nijhoff, 1978. p. 138.

${ }^{81}$ LEVINAS. E. De outro modo que ser ou para lá da essência. Trad. José Luis Pérez, Lavínia Leal Pereira. Lisboa: Centro de Filosofia da Universidade de Lisboa, 2011. p. 106.

${ }^{82}$ LEVINAS. E. Autrement qu'être ou au-delà de l'essence. Martinus Nijhoff, 1978. p. 140.

${ }^{83}$ LEVINAS. E. De otro modo que ser ou más allá de la esencia. Trad. Antonio Pintor Ramos. Salamanca: Edicones Sigueme, 2003. p. 150.

${ }^{84}$ LEVINAS. E. De outro modo que ser ou para lá da essência. Trad. José Luis Pérez, Lavínia Leal Pereira. Lisboa: Centro de Filosofia da Universidade de Lisboa, 2011. p. 106.

${ }^{85}$ LEVINAS. E. Autrement qu'être ou au-delà de l'essence. Martinus Nijhoff, 1978. p. 140.

${ }^{86}$ LEVINAS. E. De otro modo que ser ou más allá de la esencia. Trad. Antonio Pintor Ramos. Salamanca: Edicones Sigueme, 2003. p. 150.

\begin{tabular}{|c|c|l|l|l|l|}
\hline intuitio & $\begin{array}{c}\text { ISSN } \\
1983-4012\end{array}$ & Porto Alegre & Vol.11- $\mathrm{N}^{\circ} .1$ & $\begin{array}{l}\text { Julho } \\
2018\end{array}$ & p.86-104 \\
\hline
\end{tabular}


De Outro Modo Que Ser: algumas observações quanto à tradução portuguesa de

Autrement qu'être ou au-delà de l'essence

De fato, à même de... possui o sentido de ser capaz de... A versão portuguesa optou por uma tradução que consideramos um pouco imprecisa. Esse mesmo caso ocorre dois parágrafos adiante.

29. * Na página 108, a versão portuguesa deixou de fora uma frase inteira na nota de número 30. No original está: “[...] ou à la maladresse d'un comportement: il tient à la relation du prochain avec le tiers à l'égard de qui il peut être coupable, il tient à la justice naissant dans l'abnégation même devant le prochain" $"$. Na versão portuguesa se encontra: "[...] ou ao sem jeito de um comportamento: ela diz respeito à justiça nascente na própria abnegação diante do próximo" ${ }^{\circ 8}$.

30. Na página 113 está escrito: "Mas o homem simples [...]" ${ }^{89}$. O original diz: "Mais le charbonnier $[. .] "$.90 . A espanhola traduz por: "el carbonero"91. Talvez pareça que estejamos sendo muito exigentes em fazer nota dessa troca de termos porque realmente, à primeira vista, não parece fazer grandes diferenças vir a ler o homem simples ou - como seria em português - o carvoeiro, pois o carvoeiro não deixa de ser um homem simples. No entanto, é importante lembrar que no pensamento de Levinas a condição do proletário (o carvoeiro) é tema filosófico ${ }^{92}$ e não mero adorno estilístico.

31. * Na página 114 está escrito: "O razoável reenvia para uma subjetividade [...]"93. O original diz: "Le sensé renvoie à une subjectivité [...]"94. A espanhola traduz por: "Lo sentido"95. Não o que justifique essa escolha por "o razoável”. O sentido seria a melhor opção.

32. * Na página 115 , a versão portuguesa deixou de fora outra frase inteira. Na versão o original está: “[...] de silhouettes ou de phases. Prendre conscience d'un être, c'est donc toujours, pour celui-ci, être saisi à travers une idéalité et à partir d'un Dit. Même un être empirique individuel s'aborde à travers l'idéalité du logos"96. Em português se encontra somente: “[...] de silhuetas ou de fases. Até mesmo um ser empírico individual é abordado através da identidade de um logos"97.

${ }^{87}$ LEVINAS. E. Autrement qu'être ou au-delà de l'essence. Martinus Nijhoff, 1978. p. 144.

${ }^{88}$ LEVINAS. E. De outro modo que ser ou para lá da essência. Trad. José Luis Pérez, Lavínia Leal Pereira. Lisboa: Centro de Filosofia da Universidade de Lisboa, 2011. p. 108.

${ }^{89}$ LEVINAS. E. De outro modo que ser ou para lá da essência. Trad. José Luis Pérez, Lavínia Leal Pereira. Lisboa: Centro de Filosofia da Universidade de Lisboa, 2011. p. 113.

${ }^{90}$ LEVINAS. E. Autrement qu'être ou au-delà de l'essence. Martinus Nijhoff, 1978. p. 152.

${ }^{91}$ LEVINAS. E. De otro modo que ser ou más allá de la esencia. Trad. Antonio Pintor Ramos. Salamanca: Edicones Sigueme, 2003. p. 159.

92 "A indigência econômica do proletário - também sua condição de explorado - seria a desnudação absoluta do outro como outro, a de-formação até ao sem forma, para além da simples mudança de forma". LEVINAS, E. De Deus que vem à ideia. Trad. Pergentino Stefano Pivatto (coor.). Petrópolis: Editora Vozes, 2008. p. 28.

${ }^{93}$ LEVINAS. E. De outro modo que ser ou para lá da essência. Trad. José Luis Pérez, Lavínia Leal Pereira. Lisboa: Centro de Filosofia da Universidade de Lisboa, 2011. p. 114.

${ }^{94}$ LEVINAS. E. Autrement qu'être ou au-delà de l'essence. Martinus Nijhoff, 1978. p. 154.

${ }^{95}$ LEVINAS. E. De otro modo que ser ou más allá de la esencia. Trad. Antonio Pintor Ramos. Salamanca: Edicones Sigueme, 2003. p. 161.

${ }^{96}$ LEVINAS. E. Autrement qu'être ou au-delà de l'essence. Martinus Nijhoff, 1978. p.157.

${ }^{97}$ LEVINAS. E. De outro modo que ser ou para lá da essência. Trad. José Luis Pérez, Lavínia Leal Pereira. Lisboa: Centro de Filosofia da Universidade de Lisboa, 2011. p. 115.

\begin{tabular}{|c|c|c|c|c|c|}
\hline intuitio & $\begin{array}{c}\text { ISSN } \\
1983-4012\end{array}$ & Porto Alegre & Vol.11 $-\mathrm{N}^{\circ} .1$ & $\begin{array}{l}\text { Julho } \\
2018\end{array}$ & p.86-104 \\
\hline
\end{tabular}


De Outro Modo Que Ser: algumas observações quanto à tradução portuguesa de

Autrement qu'être ou au-delà de l'essence

33. * Na página 118 outro trecho deixado de fora pela versão portuguesa. No original está: “[...] l'emprise de l'Autre s'exerce sur le Même au point de l'interrompre, de le laisser sans parole: l'an-archie est persécution. L'obsession est persécution: la persécution ne constitue pas ici [...]"98 $\mathrm{Na}$ portuguesa se encontra: “[...] a ascendência do Outro exerce-se sobre o mesmo ao ponto de o interromper, de o deixar sem palavras: a an-arquia é perseguição: a perseguição não constitui aqui [...]"99.

34. * Na página 120 outro trecho fora. No original está: "La récurrence du soi-même ne se desserre pas pour se resserrer en s'éclairant ainsi comme la conscience qui s'illumine en s'interrompant [...]" ${ }^{\prime 100} \mathrm{Na}$ portuguesa se encontra: "A recorrência do si-mesmo não se desata para se atar, iluminando-se assim ao interromper-se [...]"101.

35. * Na página 121 está escrito: “A recorrência do si-mesmo reenvia aquém do presente no qual se constitui toda a identidade identificada no Dito: ela já está constituída quando o acto de constituição começa"102. O original diz: "La récurrence de soi-même renvoie en deçà du présent où toute identité identifiée dans le Dit se consti-tue: elle est d'ores et déjà constituée lorsque l'acte de constitution vient seulement pour prendre origine"103. A espanhola traduz por: "aparece tan sólo para capar el origen"104. Consideramos que versão portuguesa foi sintética demais.

36. Na página 121 está escrito: “[...] a nostalgia do retorno e a caça ao Mesmo, e o reencontro a esta claridade na qual se desenrola a consciência [...]"105. O original diz: "[...] la nostalgie du retour et la chasse au Même et les retrouvailles et cette clarté où se joue la conscience [...]"106. A espanhola traduz por: "se juega" 107 . Pensamos que deveria ter se mantido o verbo original e se traduzir por se joga, considerando que para Levinas o desenrolar da consciência é um jogo (de cartas marcadas acrescentamos).

37. * Na página 124 está escrito: “[...] a consciência na qual o ser se recolhe, como o mar recolhe as ondas que acabam de acariciar o rio" ${ }^{108}$. O original diz: "[...] la conscience où l'être se recueille

${ }^{98}$ LEVINAS. E. Autrement qu'être ou au-delà de l'essence. Martinus Nijhoff, 1978. p. 160.

${ }^{99}$ LEVINAS. E. De outro modo que ser ou para lá da essência. Trad. José Luis Pérez, Lavínia Leal Pereira. Lisboa: Centro de Filosofia da Universidade de Lisboa, 2011. p. 118.

${ }^{100}$ LEVINAS. E. Autrement qu'être ou au-delà de l'essence. Martinus Nijhoff, 1978. p. 165.

${ }^{101}$ LEVINAS. E. De outro modo que ser ou para lá da essência. Trad. José Luis Pérez, Lavínia Leal Pereira. Lisboa: Centro de Filosofia da Universidade de Lisboa, 2011. p. 120.

${ }^{102}$ LEVINAS. E. De outro modo que ser ou para lá da essência. Trad. José Luis Pérez, Lavínia Leal Pereira. Lisboa: Centro de Filosofia da Universidade de Lisboa, 2011. p. 121.

${ }^{103}$ LEVINAS. E. Autrement qu'être ou au-delà de l'essence. Martinus Nijhoff, 1978. p. 166.

104 LEVINAS. E. De otro modo que ser ou más allá de la esencia. Trad. Antonio Pintor Ramos. Salamanca: Edicones Sigueme, 2003. p. 171.

${ }^{105}$ LEVINAS. E. De outro modo que ser ou para lá da essência. Trad. José Luis Pérez, Lavínia Leal Pereira. Lisboa: Centro de Filosofia da Universidade de Lisboa, 2011. p. 121.

${ }^{106}$ LEVINAS. E. Autrement qu'être ou au-delà de l'essence. Martinus Nijhoff, 1978. p. 166.

107 LEVINAS. E. De otro modo que ser ou más allá de la esencia. Trad. Antonio Pintor Ramos. Salamanca: Edicones Sigueme, 2003. p. 171.

${ }^{108}$ LEVINAS. E. De outro modo que ser ou para lá da essência. Trad. José Luis Pérez, Lavínia Leal Pereira. Lisboa:

\begin{tabular}{|c|c|c|c|c|c|}
\hline intuitio & $\begin{array}{c}\text { ISSN } \\
1983-4012\end{array}$ & Porto Alegre & Vol.11- $\mathrm{N}^{\mathrm{o}} .1$ & $\begin{array}{l}\text { Julho } \\
2018\end{array}$ & p.86-104 \\
\hline
\end{tabular}


De Outro Modo Que Ser: algumas observações quanto à tradução portuguesa de

Autrement qu'être ou au-delà de l'essence comme la mer recueille les ondes qui viennent de lécher le rivage"109. A espanhola diz: "la orilla"110. Rivage é costa, orla, ademais, as ondas acariciarem a orla faz muito mais sentido que acariciarem $o$ rio.

38. Na página 127 está escrito: “[...] anárquico, subjetividade de uma passividade sem fundo, inteiramente feita de intimação [...]"111. O original diz: "[...] anarchique, subjectivité d'une passivité sans fond, 'toute cousue' d'assignation [...]"112. A espanhola diz: "totalmente cosida"113. Pensamos que seria melhor traduzir para algo como: toda tecida.

39. Na página 131 está escrito: “[...] o antegosto, ou, mais exactamente, da qual ela guarda $o$ sabor de boca"114. O original diz: "[...] l'avant- goût ou, plus exactement, dont elle garde l'arrièregoût" 115 . A espanhola traduz por: "el gusto antecipado"" um vestígio de mal sabor, o que faz todo o sentido aqui no pensamento desenvolvido sobre a responsabilidade a outrem.

40. Na página 133, como o original se trata de uma redundância, a versão portuguesa resolveu sintetizar a frase: “[...] estas questões só não têm sentido caso se pressuponha à partida que $o$ Eu se preocupa unicamente consigo" ${ }^{117}$. O original diz: "[...] ces questions n'ont de sens que si on a déjà supposé que le Moi n'a souci que de soi, n'est que souci de-soi." ${ }^{118}$. Consideramos que não custaria ter-se mantido a construção original.

41. * Na página 135 mais um trecho deixado de fora. No original está: "Ou le moi substitution dans sa solidité d'identique n'est-il pas solidarité commençant par porter à Autrui témoignage d'elle-même et, ainsi, avant tout, communication de la communication, signe de la donation du signe et non point transmission de n'importe quoi dans une ouverture?"119. Na portuguesa se encontra: "Ou não será o eu - substituição na sua solidez de idêntico - solidariedade que começa por dar testemunho de si mesma a Outrem, sinal da doação do sinal, e não transmissão de algo numa abertura?" ${ }^{120}$.

Centro de Filosofia da Universidade de Lisboa, 2011. p. 124.

${ }^{109}$ LEVINAS. E. Autrement qu'être ou au-delà de l'essence. Martinus Nijhoff, 1978. p. 170.

${ }^{110}$ LEVINAS. E. De otro modo que ser ou más allá de la esencia. Trad. Antonio Pintor Ramos. Salamanca: Edicones Sigueme, 2003. p. 174.

${ }^{111}$ LEVINAS. E. De outro modo que ser ou para lá da essência. Trad. José Luis Pérez, Lavínia Leal Pereira. Lisboa: Centro de Filosofia da Universidade de Lisboa, 2011. p. 127.

${ }^{112}$ LEVINAS. E. Autrement qu'être ou au-delà de l'essence. Martinus Nijhoff, 1978. p. 175.

${ }^{113}$ LEVINAS. E. De otro modo que ser ou más allá de la esencia. Trad. Antonio Pintor Ramos. Salamanca: Edicones Sigueme, 2003. p. 178.

${ }^{114}$ LEVINAS. E. De outro modo que ser ou para lá da essência. Trad. José Luis Pérez, Lavínia Leal Pereira. Lisboa: Centro de Filosofia da Universidade de Lisboa, 2011. p. 131.

${ }^{115}$ LEVINAS. E. Autrement qu'être ou au-delà de l'essence. Martinus Nijhoff, 1978. p. 182.

${ }^{116}$ LEVINAS. E. De otro modo que ser ou más allá de la esencia. Trad. Antonio Pintor Ramos. Salamanca: Edicones Sigueme, 2003. p. 184.

${ }^{117}$ LEVINAS. E. De outro modo que ser ou para lá da essência. Trad. José Luis Pérez, Lavínia Leal Pereira. Lisboa: Centro de Filosofia da Universidade de Lisboa, 2011. p. 133.

${ }^{118}$ LEVINAS. E. Autrement qu'être ou au-delà de l'essence. Martinus Nijhoff, 1978. p. 186.

${ }^{119}$ LEVINAS. E. Autrement qu'être ou au-delà de l'essence. Martinus Nijhoff, 1978. p. 189.

${ }^{120}$ LEVINAS. E. De outro modo que ser ou para lá da essência. Trad. José Luis Pérez, Lavínia Leal Pereira. Lisboa:

\begin{tabular}{|c|c|l|l|l|l|}
\hline intuitio & $\begin{array}{c}\text { ISSN } \\
1983-4012\end{array}$ & Porto Alegre & Vol.11- No.1 & $\begin{array}{l}\text { Julho } \\
2018\end{array}$ & p.86-104 \\
\hline
\end{tabular}


De Outro Modo Que Ser: algumas observações quanto à tradução portuguesa de Autrement qu'être ou au-delà de l'essence

42. * Na página 143 mais um trecho deixado fora. No original está: "La conceptualisation de ce dernier refus de conceptualisation n'est pas contemporaine de ce refus, qui transcende cette conceptualisation" 121 . Na versão portuguesa se encontra: “A conceptualização desta última recusa não é contemporânea desta recusa que transcende esta conceptualização" 122 .

43. Na página 150 está escrito: "[...] sobre o ser que se manifesta, pode, por sua vez, desempenhar o seu papel nesta manifestação do ser"123. O original diz: "[...] sur l'être qui se manifeste peut, à son tour, jouer sa partie dans cette manifestation et dans cet être" 124 . A espanhola diz: "jugar su partida" ${ }^{25}$. Mais uma vez consideramos que se poderia ter optado por algo mais próximo do original como: jogar sua partida ou jogar seu jogo.

44. Na página 156 está escrito: "Significação desadequada ao tema onde, ainda assim, ela se exibe, para se mostrar" ${ }^{26}$. O original diz: "Signification inadéquate au thème où elle s'étale cependant pour se montrer"127. A espanhola traduz por: "se instala"128. S'étale é se estender, se expandir.

45. * Na página 159 mais um trecho sacado fora. No original está: "Le dire comme aveu d'une dette précéderait-il toutes les autres façons de Dire?" 129 . A versão portuguesa assim diz: "Precederia o dizer como confissão, todas as outras formas de Dizer?"130. A versão espanhola traduz por: "confisión de una deuda"131. Em realidade, pensamos que a tradução exorcizou o d'une dette porque ela é citada na frase anterior como "reconhecimento da dívida". Mas acabou por retirar a ênfase que a frase tem, o que é trair o modo de filosofar de Levinas que disse expressamente que a ênfase é o seu método filosófico ${ }^{132}$.

Centro de Filosofia da Universidade de Lisboa, 2011. p. 135.

${ }^{121}$ LEVINAS. E. Autrement qu'être ou au-delà de l'essence. Martinus Nijhoff, 1978. p. 201.

${ }^{122}$ LEVINAS. E. De outro modo que ser ou para lá da essência. Trad. José Luis Pérez, Lavínia Leal Pereira. Lisboa: Centro de Filosofia da Universidade de Lisboa, 2011. p. 143.

${ }^{123}$ LEVINAS. E. De outro modo que ser ou para lá da essência. Trad. José Luis Pérez, Lavínia Leal Pereira. Lisboa: Centro de Filosofia da Universidade de Lisboa, 2011. p. 150.

${ }^{124}$ LEVINAS. E. Autrement qu'être ou au-delà de l'essence. Martinus Nijhoff, 1978. p. 211.

${ }^{125}$ LEVINAS. E. De otro modo que ser ou más allá de la esencia. Trad. Antonio Pintor Ramos. Salamanca: Edicones Sigueme, 2003. p. 209.

${ }^{126}$ LEVINAS. E. De outro modo que ser ou para lá da essência. Trad. José Luis Pérez, Lavínia Leal Pereira. Lisboa: Centro de Filosofia da Universidade de Lisboa, 2011. p. 156.

${ }^{127}$ LEVINAS. E. Autrement qu'être ou au-delà de l'essence. Martinus Nijhoff, 1978. p. 221.

${ }^{128}$ LEVINAS. E. De otro modo que ser ou más allá de la esencia. Trad. Antonio Pintor Ramos. Salamanca: Edicones Sigueme, 2003. p. 217.

${ }^{129}$ LEVINAS. E. Autrement qu'être ou au-delà de l'essence. Martinus Nijhoff, 1978. p. 225.

${ }^{130}$ LEVINAS. E. De outro modo que ser ou para lá da essência. Trad. José Luis Pérez, Lavínia Leal Pereira. Lisboa: Centro de Filosofia da Universidade de Lisboa, 2011. p. 159.

${ }^{131}$ LEVINAS. E. De otro modo que ser ou más allá de la esencia. Trad. Antonio Pintor Ramos. Salamanca: Edicones Sigueme, 2003. p. 220.

132 “[...] há outra maneira de justificação de uma ideia pela outra: passar de uma ideia a seu superlativo, até a sua ênfase. Eis que uma nova ideia - de forma alguma implicada na primeira - decorre ou emana da ênfase." LEVINAS, E. De Deus que vem à ideia. Trad. Pergentino Stefano Pivatto (coord.). Petrópolis, RJ: Editora Vozes, 2008. p. 126.

\begin{tabular}{|c|c|c|c|c|c|}
\hline intuitio & $\begin{array}{c}\text { ISSN } \\
1983-4012\end{array}$ & Porto Alegre & Vol.11 $-\mathrm{N}^{\circ} .1$ & $\begin{array}{l}\text { Julho } \\
2018\end{array}$ & p.86-104 \\
\hline
\end{tabular}


De Outro Modo Que Ser: algumas observações quanto à tradução portuguesa de

Autrement qu'être ou au-delà de l'essence

46. * Na página 161 está escrito: “O eu despojado pelo traumatismo da perseguição da sua subjetividade quezilenta e imperialista, que regressa ao 'eis-me' na transparência da sua opacidade, sem zonas surdas, propícias à evasão"133. O original diz: "Le moi dépouillé par le traumatisme de la persécution de sa subjectivité hargneuse et impérialiste, revenu au 'me voici' dans la transparence sans opacité, sans zones sourdes propices à l'évasion"134. A espanhola traduz por: "sin opacidad" 135 Sans é ausência de, logo: sem opacidade.

47. * Na página 161 está escrito: "É pela voz do testemunho que a glória do Infinito se glorifica" ${ }^{136}$. O original diz: "C'est par la voix du témoin que la gloire de l'Infini se glorifie"137. A versão espanhola diz: "voz del testigo"138 Témoin é aquele que dá testemunho, portanto, seria, como na versão espanhola, voz da testemunha.

48. * Na página 162 está escrito: "Que o Infinito se escapa no Dizer [...]”, e logo adiante: “[...] o testemunho no qual o sujeito sai da sua clandestinidade de sujeito - pelo qual o Infinito se escapa [...]"139. O original diz: "Que 1'Infini se passe dans le Dire [...]"140, e no mesmo parágrafo: “[...] le témoignage où le sujet sort de sa clandestinité de sujet par qui l'Infini se passe $[\ldots]]^{\prime 141}$. A espanhola diz: "se pase" ${ }^{142}$.Se passe é se passa.

49. * Na página 165 está escrito: “[...] como 'eis-me', me fez sair da invisibilidade, da sombra na qual a minha responsabilidade poderia ter sido omissa"143. O original diz: “[...] comme 'me voici', m'a fait sortir de l'invisibilité, de l'ombre où ma responsabilité aurait pu être éludée"144. Éludée é, propriamente, iludida. A versão espanhola traduz corretamente por: "eludida"145.

50. * Na página 165 mais um trecho exorcizado. No original está: “[...] cette responsabilité préalable à l'engagement est précisément l'autre-dans-le-même, inspiration et prophétisme, le se passer de

${ }^{133}$ LEVINAS. E. De outro modo que ser ou para lá da essência. Trad. José Luis Pérez, Lavínia Leal Pereira. Lisboa: Centro de Filosofia da Universidade de Lisboa, 2011. p. 161.

${ }^{134}$ LEVINAS. E. Autrement qu'être ou au-delà de l'essence. Martinus Nijhoff, 1978. p. 229.

${ }^{135}$ LEVINAS. E. De otro modo que ser ou más allá de la esencia. Trad. Antonio Pintor Ramos. Salamanca: Edicones Sigueme, 2003. p. 224.

${ }^{136}$ LEVINAS. E. De outro modo que ser ou para lá da essência. Trad. José Luis Pérez, Lavínia Leal Pereira. Lisboa: Centro de Filosofia da Universidade de Lisboa, 2011. p. 161.

${ }^{137}$ LEVINAS. E. Autrement qu'être ou au-delà de l'essence. Martinus Nijhoff, 1978. p. 229.

138 LEVINAS. E. De otro modo que ser ou más allá de la esencia. Trad. Antonio Pintor Ramos. Salamanca: Edicones Sigueme, 2003. p. 224.

${ }^{139}$ LEVINAS. E. De outro modo que ser ou para lá da essência. Trad. José Luis Pérez, Lavínia Leal Pereira. Lisboa: Centro de Filosofia da Universidade de Lisboa, 2011. p. 162.

${ }^{140}$ LEVINAS. E. Autrement qu'être ou au-delà de l'essence. Martinus Nijhoff, 1978. p. 230.

${ }^{141}$ LEVINAS. E. Autrement qu'être ou au-delà de l'essence. Martinus Nijhoff, 1978. p. 231.

142 LEVINAS. E. De otro modo que ser ou más allá de la esencia. Trad. Antonio Pintor Ramos. Salamanca: Edicones Sigueme, 2003. p. 225.

${ }^{143}$ LEVINAS. E. De outro modo que ser ou para lá da essência. Trad. José Luis Pérez, Lavínia Leal Pereira. Lisboa: Centro de Filosofia da Universidade de Lisboa, 2011. p. 165.

${ }^{144}$ LEVINAS. E. Autrement qu'être ou au-delà de l'essence. Martinus Nijhoff, 1978. p. 234.

145 LEVINAS. E. De otro modo que ser ou más allá de la esencia. Trad. Antonio Pintor Ramos. Salamanca: Edicones Sigueme, 2003. p. 228.

\begin{tabular}{|c|c|c|c|c|c|}
\hline intuitio & $\begin{array}{c}\text { ISSN } \\
1983-4012\end{array}$ & Porto Alegre & Vol.11- $\mathrm{N}^{\mathrm{o}} .1$ & $\begin{array}{l}\text { Julho } \\
2018\end{array}$ & p.86-104 \\
\hline
\end{tabular}


De Outro Modo Que Ser: algumas observações quanto à tradução portuguesa de

Autrement qu'être ou au-delà de l'essence l'Infini""146. A versão portuguesa retira o de l'Infini, terminando a frase simplesmente assim: "[...] esta responsabilidade prévia ao compromisso, é precisamente o-outro-no-mesmo, inspiração e profetismo, o passar-se" ${ }^{147}$.

51. * Na página 166 está escrito: "Mas enquanto palavra extra-ordinária, a única que não apaga nem absorve o seu Dizer, que só pode manter-se como simples palavra"148. O original diz: "Mais mot extra-ordinaire, le seul qui n'éteigne ni n'absorbe son Dire, mais qui ne peut rester simple mot" "49. A espanhola traduz por: "y que no puede permanecer como mera palavra"150. A espanhola traduziu corretamente a frase na negativa.

52. Na página 169 está escrito: "Na re-presentação, o Infinito desmentir-se-ia sem ambiguidade, como se fosse um objeto 'infinito' que a subjetividade tenta abordar, passando-lhe ao lado"151. O original diz: "Dans la re-présentation l'Infini se démentirait sans ambiguïté comme s'il était un objet 'infini' que la subjectivité tente d'aborder en le manquant"152. A espanhola traduz por: "como algo ausente 153 . O mesmo caso do ponto 27. A versão espanhola nos parece estar mais próxima do original. Outra alternativa poderia ser: como algo perdido.

53. * Na página 169 está escrito: “[...] a menos que ele tenha reunido o não-reunível; que a apofânsis - o Dito -, mais formal que o formal, já não seja enunciado do ser, nem sequer enunciado ontológico de 'ontologia formal'; a menos que ele seja irredutível à essência; mas que, a ela, semelhante pela ostentação - pela própria indiscrição que ela torna possível -, ele já seja hipóstase de "éon"”154. $\mathrm{O}$ original diz: “[...] à moins qu'il n'ait assemblé l'inassemblable; que l'apophansis le Dit plus formel que le formel ne soit plus en rien énoncé de l'être, pas même énoncé ontologique d' 'ontologie formelle'; qu'il ne soit irréductible à l'essence, mais que, semblable à elle par l'ostension par l'indiscrétion même qu'il rend possible il ne soit déjà hypostase d' "éon"” 155 . As frases se encontram na negativa, a tradução portuguesa, erroneamente, as deixou na afirmativa. A versão espanhola conservou na negativa ${ }^{156}$.

${ }^{146}$ LEVINAS. E. Autrement qu'être ou au-delà de l'essence. Martinus Nijhoff, 1978. p. 235.

${ }^{147}$ LEVINAS. E. De outro modo que ser ou para lá da essência. Trad. José Luis Pérez, Lavínia Leal Pereira. Lisboa: Centro de Filosofia da Universidade de Lisboa, 2011. p. 165.

${ }^{148}$ LEVINAS. E. De outro modo que ser ou para lá da essência. Trad. José Luis Pérez, Lavínia Leal Pereira. Lisboa: Centro de Filosofia da Universidade de Lisboa, 2011. p. 166.

${ }^{149}$ LEVINAS. E. Autrement qu'être ou au-delà de l'essence. Martinus Nijhoff, 1978. p. 236.

${ }^{150}$ LEVINAS. E. De otro modo que ser ou más allá de la esencia. Trad. Antonio Pintor Ramos. Salamanca: Edicones Sigueme, 2003. p. 230.

${ }^{151}$ LEVINAS. E. De outro modo que ser ou para lá da essência. Trad. José Luis Pérez, Lavínia Leal Pereira. Lisboa: Centro de Filosofia da Universidade de Lisboa, 2011. p. 169.

152 LEVINAS. E. Autrement qu'être ou au-delà de l'essence. Martinus Nijhoff, 1978. p. 240.

${ }^{153}$ LEVINAS. E. De otro modo que ser ou más allá de la esencia. Trad. Antonio Pintor Ramos. Salamanca: Edicones Sigueme, 2003. p. 233.

${ }^{154}$ LEVINAS. E. De outro modo que ser ou para lá da essência. Trad. José Luis Pérez, Lavínia Leal Pereira. Lisboa: Centro de Filosofia da Universidade de Lisboa, 2011. p. 169.

${ }^{155}$ LEVINAS. E. Autrement qu'être ou au-delà de l'essence. Martinus Nijhoff, 1978. p. 242.

${ }^{156}$ LEVINAS. E. De otro modo que ser ou más allá de la esencia. Trad. Antonio Pintor Ramos. Salamanca:

\begin{tabular}{|c|c|l|l|l|l|}
\hline intuitio & $\begin{array}{c}\text { ISSN } \\
1983-4012\end{array}$ & Porto Alegre & Vol.11- $\mathrm{N}^{\circ} .1$ & $\begin{array}{l}\text { Julho } \\
2018\end{array}$ & p.86-104 \\
\hline
\end{tabular}


De Outro Modo Que Ser: algumas observações quanto à tradução portuguesa de

Autrement qu'être ou au-delà de l'essence

54. Na página 171, a palavra Deus no primeiro parágrafo ${ }^{157}$ está escrita com letra minúscula, no original ${ }^{158}$ está em maiúscula. Isso pode ter sido relapso ou forma de protesto. Caso tenha sido uma forma de protesto, cabe notar que a boa ética nos ensina que o lugar de fazer protesto é no próprio texto e não no dos outros.

55. * Na página 172, a versão portuguesa - num acesso de fidelidade radical ao texto original fora de hora - copiou tal qual a nota de rodapé sem fazer a devida correção com a edição. A nota de número $25 \mathrm{diz}$ assim na versão portuguesa: "Cf. mais acima, p.235, nota sobre a ananké stenai"159. É o mesmo que se encontra na edição francesa ${ }^{160}$, porém ocorre que a nota a que essa nota se refere está em outra página da edição portuguesa; ela se encontra na página 165 e é a de número 21.

56. * Na página 173 está escrito: “A justiça não é de todo uma degradação da obsessão [...]"161. O original diz: "En aucune façon la justice n'est une dégradation de l'obsession [...]"162. A espanhola traduz por: "De ninguna manera"163. A espanhola traduz certa a expressão. O não é de todo dá a entender que de algum modo a justiça possa ser degradação da obsessão.

57. Na página 178 está escrito: "Espiritualidade na qual tem lugar o Infinito [...]"164. O original diz: "Spiritualité où se passe l'infini [...]"165. A espanhola traduz por: "Espiritualidad en la que transcurre lo Infinito [...]"166. Ainda que não nos pareça ser propriamente errada a escolha da portuguesa, cremos que algo em português como onde se passa seria mais feliz, pois se evitaria a sugestão de "repouso" do Infinito que tem lugar possui.

58. * Na página 182 está escrito: “[...] se ele fala - não deixa, por isso mesmo, de falar de si e de falar do discurso onde há pouco ele falava [...]”167. O original diz: “[...] se parle il n'en parle pas moins et parle du discours où tout à l'heure il parlait [...]"168. A versão espanhola traduz assim: "[...] se habla, no

Edicones Sigueme, 2003. p. 234.

${ }^{157}$ Cf. LEVINAS. E. De outro modo que ser ou para lá da essência. Trad. José Luis Pérez, Lavínia Leal Pereira. Lisboa: Centro de Filosofia da Universidade de Lisboa, 2011. p. 171.

${ }^{158}$ LEVINAS. E. Autrement qu'être ou au-delà de l'essence. Martinus Nijhoff, 1978. p. 244.

${ }^{159}$ LEVINAS. E. De outro modo que ser ou para lá da essência. Trad. José Luis Pérez, Lavínia Leal Pereira. Lisboa: Centro de Filosofia da Universidade de Lisboa, 2011. p. 172.

${ }^{160}$ LEVINAS. E. Autrement qu'être ou au-delà de l'essence. Martinus Nijhoff, 1978. p. 247.

${ }^{161}$ LEVINAS. E. De outro modo que ser ou para lá da essência. Trad. José Luis Pérez, Lavínia Leal Pereira. Lisboa: Centro de Filosofia da Universidade de Lisboa, 2011. p. 173.

162 LEVINAS. E. Autrement qu'être ou au-delà de l'essence. Martinus Nijhoff, 1978. p. 248.

163 LEVINAS. E. De otro modo que ser ou más allá de la esencia. Trad. Antonio Pintor Ramos. Salamanca: Edicones Sigueme, 2003. p. 239.

${ }^{164}$ LEVINAS. E. De outro modo que ser ou para lá da essência. Trad. José Luis Pérez, Lavínia Leal Pereira. Lisboa: Centro de Filosofia da Universidade de Lisboa, 2011. p. 178.

${ }^{165}$ LEVINAS. E. Autrement qu'être ou au-delà de l'essence. Martinus Nijhoff, 1978. p. 256.

${ }^{166}$ LEVINAS. E. De otro modo que ser ou más allá de la esencia. Trad. Antonio Pintor Ramos. Salamanca: Edicones Sigueme, 2003. p. 245.

${ }^{167}$ LEVINAS. E. De outro modo que ser ou para lá da essência. Trad. José Luis Pérez, Lavínia Leal Pereira. Lisboa: Centro de Filosofia da Universidade de Lisboa, 2011. p. 182.

${ }^{168}$ LEVINAS. E. Autrement qu'être ou au-delà de l'essence. Martinus Nijhoff, 1978. p. 262.

\begin{tabular}{|c|c|c|c|c|c|}
\hline intuitio & $\begin{array}{c}\text { ISSN } \\
1983-4012\end{array}$ & Porto Alegre & Vol.11- No.1 & $\begin{array}{c}\text { Julho } \\
2018\end{array}$ & p.86-104 \\
\hline
\end{tabular}


De Outro Modo Que Ser: algumas observações quanto à tradução portuguesa de

Autrement qu'être ou au-delà de l'essence por ello habla menos y habla del discurso en el cual entonces hablaba [...]"169 Consideramos que a versão espanhola fez escolha mais acertada.

59. Na página 182 está escrito: "Virtude que se expõe no dito poético [...]"170. O original diz: "Vertu qui se met à $n u$ dans le dit poétique [...]"171. A versão espanhola traduz por: "Virtud que aparece desnuda en el dicho poético [...]"172. A versão espanhola foi mais feliz, mas se met à nu expressa uma atividade e não meramente uma constatação, sendo assim: virtude que se desnuda.

60. Na página 194 Levinas cita uma passagem bíblica sem fazer referência, talvez porque demasiado conhecida. É de Eclesiastes cap.I, versículo 1: "Vanidades das vanidades, tudo é vaidade, nada há de novo debaixo do sol"173.

61. Na página 194 está escrito: “[...] na transcendência que tem aí o seu lugar ou que aí se supera [...]"174. O original diz: "[...] dans la transcendance qui s'y passe ou s'y dépasse [...]"175. A espanhola traduz por: "que aquí se passa o se supera"176. Dépasse é ultrapassar, passar adiante de..., quando, por exemplo, se ultrapassa um carro no trânsito. Talvez uma alternativa melhor seria: na transcendência que aí se passa ou ultrapassa.

\section{Considerações Finais}

Mesmo que a versão portuguesa tenha apresentado essa série de deficiências, não se pode lhe tirar o mérito em ter assumido a tarefa de trazer por primeira vez na língua portuguesa essa grande obra de Levinas, passados quase quarenta anos de sua publicação ${ }^{177}$, e que, como dito no início desse artigo, apresenta dificuldades pelo próprio estilo hermético do autor, assim como também por seu pensamento, um tanto quanto heterodoxo no ambiente filosófico. Limitações, deficiências ou dificuldades não são razões suficientes para que se se detenha na realização da tarefa ética. Em um mundo ofendido como o nosso, onde falta o pão às bocas, em que o pensamento é, literalmente, patrocinado e assim sequestrado

${ }^{169}$ LEVINAS. E. De otro modo que ser ou más allá de la esencia. Trad. Antonio Pintor Ramos. Salamanca: Edicones Sigueme, 2003. p. 251.

${ }^{170}$ LEVINAS. E. De outro modo que ser ou para lá da essência. Trad. José Luis Pérez, Lavínia Leal Pereira. Lisboa: Centro de Filosofia da Universidade de Lisboa, 2011. p. 182.

${ }^{171}$ LEVINAS. E. Autrement qu'être ou au-delà de l'essence. Martinus Nijhoff, 1978. p. 263.

${ }^{172}$ LEVINAS. E. De otro modo que ser ou más allá de la esencia. Trad. Antonio Pintor Ramos. Salamanca: Edicones Sigueme, 2003. p. 251.

${ }^{173}$ LEVINAS. E. De outro modo que ser ou para lá da essência. Trad. José Luis Pérez, Lavínia Leal Pereira. Lisboa: Centro de Filosofia da Universidade de Lisboa, 2011. p. 194.

${ }^{174}$ LEVINAS. E. De outro modo que ser ou para lá da essência. Trad. José Luis Pérez, Lavínia Leal Pereira. Lisboa: Centro de Filosofia da Universidade de Lisboa, 2011. p. 194.

${ }^{175}$ LEVINAS. E. Autrement qu'être ou au-delà de l'essence. Martinus Nijhoff, 1978. p. 281.

${ }^{176}$ LEVINAS. E. De otro modo que ser ou más allá de la esencia. Trad. Antonio Pintor Ramos. Salamanca: Edicones Sigueme, 2003. p. 267.

${ }^{177}$ Considerando o ano da edição da tradução: 2011.

\begin{tabular}{|c|c|c|c|c|c|}
\hline intuitio & $\begin{array}{c}\text { ISSN } \\
1983-4012\end{array}$ & Porto Alegre & Vol.11 $-\mathrm{N}^{\circ} .1$ & $\begin{array}{l}\text { Julho } \\
2018\end{array}$ & p.86-104 \\
\hline
\end{tabular}


De Outro Modo Que Ser: algumas observações quanto à tradução portuguesa de

Autrement qu'être ou au-delà de l'essence pela Realpolitik e pelas razões ardilosas ${ }^{178}$, usar de todo o esforço que há em si e fora de si, que se nos excede para outro modo que ser, é inspiração ${ }^{179}$ suficiente para que se arrisque na loucura pela justiça ainda que isso se concretize na singela, mas não menos importante, tradução de um livro. Espera-se, por fim, que este trabalho ajude na melhor recepção do pensamento de Emmanuel Levinas na língua portuguesa e que possa incentivar outros e outras estudantes a irem ao encontro traumático de seus textos, mesmo que não saibam sua língua, pois, de qualquer jeito, a língua do outro sempre será isso, do outro e sempre estrangeira.

\section{Referências}

ECO, U. Decir casi lo mismo. Trad: Helena Lozano Meireles. Barcelona: Debolsillo, 2009.

GAUER, R. M. C. (Org.) Criminologia e Sistemas jurídico-penais contemporâneos II. - Dados eletrônicos. - Porto Alegre: EDIPUCRS, 2010.

GULLAR, F. Toda poesia:1950-1980. Rio de Janeiro: Civilização Brasileira, 1981. $2^{\text {a }}$ Edição (Coleção Vera Cruz. Literatura Brasileira, volume 300).

HUSSERL, E. Meditações cartesianas e Conferências de Paris. Trad: Pedro M. S. Alves. - 1. ed. - Rio de janeiro: Forense, 2013.

LEVINAS. E. Autrement qu'être ou au-delà de l'essence. Martinus Nijhoff, 1978.

LEVINAS. E. De otro modo que ser ou más allá de la esencia. Trad. Antonio Pintor Ramos. Salamanca: Edicones Sigueme, 2003.

LEVINAS, E. De Deus que vem à ideia. Trad: Marcelo Fabri, Marcelo Luiz Pelizzoli, Evaldo Antônio Kuiava, Pergentino Stefano Pivatto (coordenador e revisor) - 2. ed. - Petrópolis: Vozes, 2008.

LEVINAS. E. De outro modo que ser ou para lá da essência. Trad. José Luis Pérez, Lavínia Leal Pereira. Lisboa: Centro de Filosofia da Universidade de Lisboa, 2011.

LEVINAS, E. Deus, a Morte e o Tempo. Trad.: Fernanda Bernardo. Lisboa: Edições 70, 2012.

SEBBAH, François-David. Levinas. Trad: Guilherme João de Freitas Teixeira. São Paulo: Estação Liberdade, 2009.

\section{Instrumentos de trabalho}

GÁLVEZ, J. A. (coord.). Dicionário Larousse francês/português, português/francês: mini / - 2.ed. - São Paulo: Larousse Brasil, 2008.

MOLINER, M. Diccionario de sinónimos y antónimos. Madrid: Editorial Gredos, 2009.

178 "A razão ardilosa cerca-se a priori de cuidados e credibilidades; procura, antes de mais nada, não chocar, pois qualquer choque é perigoso. Imbuída da difícil tarefa de sustentar a violência e vulgaridade do mundo, essa massa volátil e espasmódica, ao estilo de um exoesqueleto altamente cerebral, é e tem de se mostrar inteligente; o meiotom intelectual é seu registro, pois não pode mostrar a que veio, mas apenas o que transparece em sua retórica de intenções". SOUZA, R. T. "O nervo exposto - Por uma crítica da ideia de razão desde a racionalidade ética". In. GAUER, R. M. C. (Org.) Criminologia e Sistemas jurídico-penais contemporâneos II. - Dados eletrônicos. Porto Alegre: EDIPUCRS, 2010. p. 111.

179 "Ascendência que eu encontro na urgência extrema que apela ao meu socorro, ao ponto de eu chegar sempre demasiado tarde, pois não dispõe de tempo para me esperar. Esta maneira de me reivindicar, de em mim me agitar, podemos chamar-lhe [...] inspiração". LEVINAS, E. Deus, a Morte e o Tempo. Trad.: Fernanda Bernardo. Lisboa: Edições 70, 2012. p. 217.

\begin{tabular}{|c|c|l|l|l|l|}
\hline intuitio & $\begin{array}{c}\text { ISSN } \\
1983-4012\end{array}$ & Porto Alegre & Vol.11- $\mathrm{N}^{\circ} .1$ & $\begin{array}{l}\text { Julho } \\
2018\end{array}$ & p.86-104 \\
\hline
\end{tabular}

